BULLETIN Bulletin hispanique

HISPANIQUE Université Michel de Montaigne Bordeaux

112-1| 2010

Actes du Colloque « langue, littérature, littéralité »

Sables d'exil. Les républicains espagnols dans les camps d'internement au Maghreb (1939-1945)

Mare Nostrum, Perpignan, 2009

\title{
Rose Duroux
}

\section{(2) OpenEdition}

\section{Journals}

Édition électronique

URL : http://journals.openedition.org/bulletinhispanique/1209

DOI : 10.4000/bulletinhispanique.1209

ISSN : 1775-3821

Éditeur

Presses universitaires de Bordeaux

Édition imprimée

Date de publication : 1 juin 2010

Pagination : 458-461

ISBN : 978-2-86781-692-5

ISSN : 0007-4640

Référence électronique

Rose Duroux « Sables d'exil. Les républicains espagnols dans les camps d'internement au Maghreb

(1939-1945) », Bulletin hispanique [En ligne], 112-1 | 2010, mis en ligne le 04 janvier 2013, consulté le 19 avril 2019. URL : http://journals.openedition.org/bulletinhispanique/1209; DOI : 10.4000/

bulletinhispanique.1209 
reunirán en Prosas propicias, su obra prima. Y toda esta trayectoria poética nos la presenta Alarcón Sierra con gran soltura y sutileza, sin perder de vista nunca la cuestión contemplativa y humana que yace en los cimientos de la poesía de Vivanco. En otras palabras, este libro resume y deja claramente delineado cómo llega a ser poeta Vivanco, particularmente en términos de su ambiente sociohistórico y sus preocupaciones personales. A este respecto, habría sido incluso más completo el libro si hubiera dedicado Alarcón Sierra unas páginas más a los fundamentos filosóficos de la obra de Vivanco a través de aquellas figuras tan transcendentales en su pensar como lo fueron Unamuno, A. Machado, Heidegger y Zubiri, pero se entiende que abarcar estos gigantes del pensamiento hubiera requerido otro tipo de aproximación y hasta otro tipo de libro.

Para el lector o estudioso de la obra de Vivanco, Luis Felipe Vivanco: contemplación y entrega de Alarcón Sierra es una lectura fundamental. En este libro, acompañado de su antología poética con una muestra de los poemas más significativos del poeta entre 1929 y 1976, se encontrará tanto Vivanco el poeta como Vivanco el hombre. Y estas dos facetas, que en verdad son una sola, hacen que el poeta reviva en este libro y recobre algo del reconocimiento perdido hasta hoy.

\section{Nicolás FERNÁNDEZ-MEDINA}

Sables d'exil. Les républicains espagnols dans les camps d'internement au Maghreb (1939-1945), Andrée Bachoud \& Bernard Sicot (dir.), no spécial de : Exils et migrations ibériques au $\mathrm{XX}^{\mathrm{e}}$ siècle, $\mathrm{n}^{\circ} 3$ (nouvelle série), Université Paris Ouest Nanterre La Défense (BDIC/CERMI/ CRIIA). - Perpignan, Mare Nostrum, 2009, 316 p. - ISBN : 978-2-908476-72-9 EAN : 9782908476729

L'ouvrage dirigé par Andrée Bachoud et Bernard Sicot sur l'exil des républicains espagnols vers l'Afrique du Nord, pendant et surtout à la fin de la Guerre d'Espagne, vient combler un vide historiographique important.

La préface et les huit chapitres ont été confiés aux spécialistes de la question. Le livre s'ouvre sur un prologue de Christine Levisse-Touzé dont on connaît l'incontournable' L'Afrique du Nord dans la guerre, 1939-1945. Le but est de montrer comment cet exil vers l'autre rive de la Méditerranée, bien que très inférieur en nombre au grand exode que connut la France, éclaire d'un jour nouveau les grands enjeux du siècle dernier et en particulier le passage 
de l'internement politique d'exception, sous la Seconde République, à la politique d'exclusion, sous Vichy. Pourquoi un tel exil est-il à ce point méconnu ? Plusieurs raisons à cela, explique Andrée Bachoud : l'ampleur du Maghreb ; les différences sociopolitiques entre l'Algérie, le Maroc et la Tunisie ; la disparité des modalités de l'accueil ; les possibilités d'initiative de chacun de ces pays du fait de l'absence de l'occupant allemand même si la politique vis-à-vis des réfugiés dépend de la France jusqu'en novembre 1942. Le sort des réfugiés est d'autant plus difficile à cerner que la réception qui leur est faite peut aller de l'accueil individuel à l'internement massif et que la situation se complexifie du fait des changements de statut, des transferts constants - et davantage encore à partir du débarquement anglo-américain.

Pour saisir cette main d'œuvre mouvante les auteurs ont mis à contribution les archives sérielles du Centre des Recherches d'Outre-Mer (CAOM), la correspondance consulaire (MAE espagnol ; Quai d'Orsay), les archives orales, l'écriture autobiographique, etc. Après un tableau général établi par Andrée Bachoud, les diverses modalités de l'accueil sont examinées avec des focales différentes. Une fois exposés les fondements du vichysme colonial, Jacques Cantier aborde les camps d'Algérie à travers une législation d'autant plus abondante que la politique d'internement est au cœur de la Révolution nationale de Vichy. Sont examinées les différentes générations de " camps " et " chantiers de travail " (chemin de fer, routes, mines). Le débarquement anglo-saxon n'entraîne pas le démantèlement immédiat de l'internement : un vichysme sous protectorat américain semble s'accommoder de l'héritage de la période précédente, du moins jusqu'en mai 1943. Les camps ne se vident que peu à peu, le dernier n'étant " libéré " qu'en juillet.

Un éclairage spécial est porté sur Oran, la plus espagnole des villes d'Algérie. Les nouveaux arrivants y bénéficient souvent de contacts, la vague migratoire provenant des dernières villes républicaines : Alicante, Almería, Valence, Carthagène. Suzanne Aubrespy expose les difficultés administratives d'accostage, mesure les arrivées, cartographie les implantations, illustre par des photos, établit les pourcentages des obtentions de visa pour reémigrer (notamment vers l'Amérique Latine) ou retourner en Espagne. Alfred Salinas, grâce à une enquête directe auprès des témoins, à Oran, montre que la communauté espagnole néo-française, bien que massivement de sensibilité nationaliste, témoigne à l'égard des réfugiés, au début, une solidarité active qui finira par s'étioler (la guerre d'Algérie accentuera encore la fracture); quant au consul général d'Espagne, Barnabé Toca, il leur ouvre, non sans arrière-pensées, les services caritatifs de l'Auxilio social. 
Anne Dulphy fait une étude fine des " centres d'hébergement " (administration civile) et des " camps d'internement " (administration militaire) qu'elle passe au crible pour la période mars 1939-mai 1940 et pour l'Algérie. Elle met au jour la totale improvisation dans laquelle se fit l'accueil des quelque 10000 réfugiés espagnols ainsi que la spécificité coloniale dans la vigilance dont firent preuve les autorités face au risque, d'une part, de concurrencer la main d'œuvre locale et, d'autre part, de favoriser la "résurrection du sentiment espagnol dans le milieu ethnique d'origine ibérique ». Faute de locaux vides, on eut recours aux établissements militaires d'où l'importance numérique des "internés " par rapport aux " hébergés ". Les centres d'hébergement, sis pour la plupart dans la région d'Orléansville, offrent des locaux insalubres à quelques dizaines ou centaines de réfugiés - selon les cas. Les camps d'internement - Relizane et Boghari - , réservés en principe à ceux qui ont servi dans l'armée républicaine, se situent, eux, à l'écart des centres urbains, à proximité d'une garnison et sous l'autorité militaire. Le décret-loi du 12 avril 1939 favorise une mise au travail généralisée : les «internés " sont alors incorporés dans une douzaine de Compagnies de Travailleurs Étrangers (CTE) et les "inaptes " envoyés dans un centre d'hébergement. Avec la débâcle et la démobilisation, l'objectif d'utiliser une main d'œuvre bon marché au profit de l'effort de la nation en guerre cède la place à l'impératif d'écarter une force concurrentielle en l'encadrant dans des Groupes de Travailleurs Étrangers (GTE) conçus en Afrique du Nord dans une logique d'exclusion.

C'est d'après les archives de Carlos Esplá Rizo, né à Alicante en 1895, journaliste et homme politique bien connu, que Margot Poigné étudie la gestion des demandes d'asile par la JARE (Junte d'aide aux républicains espagnols), sous le patronage de la Légation du Mexique - des demandes gérées dans un premier temps par un organisme rival, le SERE (Service d'évacuation des républicains espagnols). Entre 1500 et 1600 Espagnols d'Afrique du Nord rejoignirent le Mexique. L'accent est mis sur les difficultés de la gestion à distance, les dysfonctionnements internes, les aléas des tris d'ordre géographique et/ou politique et les critiques dont la JARE devient la cible dès 1942.

Bernard Sicot, en faisant parler méthodiquement archives et témoignages, réalise un gros plan sur le camp de Djelfa créé dans le Haut-Atlas en 1941. Ce camp spécial, trop visible après le débarquement allié, sera fermé en mars 1943 (pour devenir un camp de prisonniers de guerre). Les « internés administratifs » sont, pour l'essentiel, des interbrigadistes et des républicains 
espagnols. Parmi eux, l'écrivain Max Aub, qui a produit plusieurs récits sur ce lieu ou non-lieu, ainsi qu'un recueil de poèmes, Journal de Djelfa, grâce auxquels le lecteur appréhende de l'intérieur le triste ordinaire du camp : un tableau sombre que nuancent des rapports externes. Aub va jusqu'à estimer, dans certains textes inédits, les bénéfices réalisés par le chef du camp, Caboche, sur le dos des internés (irrégularités pour lesquelles ce dernier ne sera guère inquiété). Dans son long journal-poème expressionniste, Aub noircit le trait pour traduire l'insulte faite à l'homme ; les passages choisis et traduits par Bernard Sicot complètent le tableau, tel ce portrait au vitriol du geôlier métonymique "Gravelle, vrai fils de pute/fiel sillonné de vinaigre ".

Cette exhumation de l'histoire des camps du Maghreb, où l'Algérie occupe la plus large place, se clôt sur un journal intime : Les Cahiers d'Antonio Blanca, traduit de l'espagnol par María Luisa Broseta. Le diariste, un homme jeune, cultivé, grand lecteur, a tenu son journal du 2 avril 1939 au 27 décembre 1940. Il retrace l'embarquement déchirant d'Alicante, le passage par la caserne Berthézène à Orléansville, l'arrivée au camp de Boghari aux portes du désert (pour retrouver son frère) et, enfin sans barbelés, le centre d'hébergement de Cherchell. Ce journal est un document digne d'intérêt même si l'auteur pratique l'autocensure et utilise des initiales afin de ne compromettre personne. Un journal au reste peu compromettant puisque Antonio Blanca a abandonné tout militantisme politique. Carlos Seco Serrano a dit l'intérêt du journal intime pour l'historien auquel il fournit un matériau précieux "même quand celui qui rédige pense à l'image que ces pages donneront de lui si on vient à les publier ". On lit ici l'insoutenable promiscuité, l'insalubrité, la chaleur accablante, les sentiments qui agitent les réfugiés jusqu'à la folie, les connivences régionales (cf. "le trio alicantin»). Ce n'est pas un réquisitoire mais une écriture pour résister, pour être par la pensée avec les siens (la jeune épouse et l'enfant) et surtout pour s'abstraire de ce "pourrissoir d'âmes". Le leitmotiv est la correspondance, la missive envoyée " comme un SOS angoissé " ("j'écris beaucoup de lettres pour tout tenter »), l'attente obsessionnelle de la réponse qui annoncera, enfin, le départ vers Cuba, le Mexique ou le Chili. Attente vaine pour Antonio Blanca qui s'installera définitivement à Boghari, avec sa famille.

Une somme, donc, que ces Sables d'exil, et un outil indispensable pour qui veut comprendre l'accueil fait aux réfugiés espagnols en Afrique du Nord et notamment dans l'Algérie des années 1939-1943.

Rose DUROUX 